\title{
Seasonality of Climate Drives the Number of Tree Hollows in Eastern Australia: Implications of a Changing Climate
}

\author{
John T. Hunter \\ School of Behavioral, Cognitive and Social Sciences, University of New England, Armidale, NSW 2351, Australia \\ Correspondence should be addressed to John T. Hunter; jhunter8@bigpond.com
}

Received 12 March 2015; Accepted 26 March 2015

Academic Editor: Béla Tóthmérész

Copyright ( 92015 John T. Hunter. This is an open access article distributed under the Creative Commons Attribution License, which permits unrestricted use, distribution, and reproduction in any medium, provided the original work is properly cited.

\begin{abstract}
Tree hollow number is investigated across an altitudinal and climatic gradient in eastern Australia. The relationship between seasonal climate and local site factors to hollow number at a regional scale was investigated. Moisture retention, rainfall, and solar radiation during the summer period were the highest contributing factors to hollow number in the model presented. The relationship of hollow number with the significant variables was unimodal in nature with either extreme causing a decline within the region. The results indicate that increased seasonality of rainfall, solar radiation, and temperatures as predicted by anthropogenic climate change will cause a shift in the optimal location for hollow number. Change in tree hollows is reliant on taxonomic replacement through dispersal and establishment and subsequently time to allow individuals to mature. The reduction in this resource stimulated by changes in seasonality predicted within the ensuing decades is likely to cause a loss of hollows across the landscape with the resource not being replaced for hundreds of years. The number of hollows within a landscape may drastically reduce due to climate change alone irrespective of tree clearing rates.
\end{abstract}

\section{Introduction}

Functional attributes of our woodland and forest ecosystems are dwindling at an accelerated rate due to anthropogenic clearing and fragmentation. The loss of these attributes of woodlands and forests necessarily requires species to change their functional responses to environment causing changes in interactions between species $[1,2]$ but is also a key driver of extinctions. Hollows are an important functional resource within woodlands and forests worldwide [3-7]. In Australia hollows are used by 290 terrestrial vertebrate species, a number of which use them obligately [7-10]. Australian vertebrate species are known to increase the size of hollow entrances once a hollow has formed; however, excavating species (e.g., Wood Peckers) are lacking; thus formation is a long term process [7]. Trees in an undisturbed state will generally form hollows at the point at which growth rate slows and branches are shed [9]. Hollows will also form on individuals that are physiologically stressed [11] or exposed to stochastic damaging events (e.g., fire and windstorm) $[9,12]$. Thus, hollows in the Australian context are largely initiated by injuries that broach the sapwood and expose the heartwood to decay, which is often further enhanced by termites. Formation of hollows takes considerable time once an injury has occurred and the older an individual is the more likely hollows will have time to develop. Dead stems on live trees have also been found to have more hollows [13]. In addition, larger older trees have been exposed to the environment for a longer period and therefore to the stochastic initiating events that cause hollow formation and development $[9,14]$.

Evidence is accumulating that species identity plays a significant role in the variation of hollow density. Eyre [15] found a greater number of hollow bearing trees within communities dominated by Corymbia intermedia and Corymbia trachyphloia than in those dominated by Corymbia citriodora and Eucalyptus fibrosa. Angophora leiocarpa has also been described as acquiring hollows at a smaller size class than Corymbia trachyphloia with Eucalyptus tereticornis, Corymbia citriodora, Eucalyptus crebra, and Eucalyptus fibrosa all requiring much larger stem diameters before hollows were recorded [15]. Bennett et al. [14] and Rayner et al. [13] also suggested that Eucalyptus microcarpa produced hollows at a faster rate than Eucalyptus camaldulensis and that Eucalyptus 
viridis, Allocasuarina luehmannii, Callitris glaucophylla, and Eucalyptus macrorhyncha rarely formed hollows. Munks et al. [16] indicated that forests dominated by Eucalyptus obliqua formed more hollows compared to other forest types within their study region. Bennett et al. [14] and Eyre [15] proposed that taxon differences in hollow formation susceptibility were due to growth rates, with slower growing species forming more hollows for a given size than faster growing species. Vines [17] suggested that trees with thinner bark (gum and box bark) are more susceptible to damage from fire and bark thickness was negatively correlated to surrogates for physiological stress [18] and therefore bark type and thickness may also influence the chance of hollows forming. Thus within the Australian context, identity of overstorey species is an important factor in the distribution and abundance of this significant functional resource within the landscape.

Physiographic position has also been implicated as a factor influencing hollow number. Lindenmayer et al. [8] and Soderquist and Mac Nally [19] both found an increase in trees with hollows in lower topographic positions such as gullies compared to mid-slopes and ridges. In contrast Lindenmayer et al. [12] suggested that slopes, particularly steeper slopes, had a greater number of hollows due to increased fire intensity, exposure, reduced site productivity, and hence slower growth rates. Eyre [15] also found more hollows on slopes than in gullies or ridge tops. Whether these patterns were due to the physical characteristics, compositional differences, or a combination of both is not entirely clear from the research conducted. Lindenmayer et al. [8] and Bennett et al. [14] found that a decrease in rainfall and an increase in temperature were correlated to an increase in the number of hollows per hectare. However, it was also not tested whether there was a direct link to compositional differences within these patterns. While climatic influences on hollow occurrence have been investigated, the seasonal aspects of climate have been less well considered. Changes in the seasonality of climate are some of the more significant aspects of climate change in many locations [20]. Seasonality of climatic variables has been shown to be a major factor in the evolution of plant life history traits, species composition, and competition worldwide but not in terms of changing the ratio or location of vital functional attributes important for species survival [21-24].

Gibbons and Lindenmayer [25] considered that 80$90 \%$ of the hollow resource of woodlands within Australia had been depleted in agricultural areas. Understanding the multifactorial aspects correlated to occurrence and number of these vital functional attributes is of great importance. Within this study the distribution of hollow resources was investigated across sites primarily within the national reserve system of Australia. It is predicted that aspects of climate seasonality will be major contributing factors to the number of hollows through influence on species composition. Mean average climate and seasonal climate attributes along with local landscape variables are analysed within a summer dominant rainfall zone for their correlated contribution to hollow number. It is thus tested whether, at a regional scale, a more nuanced approach that includes seasonality is of importance in understanding the current and future abundance and distribution of this important functional resource.

\section{Methods}

2.1. Study Area. The study was undertaken primarily within the New England Tablelands, Nandewar, and Brigalow Belt South Bioregions [26] within New South Wales (Figure 1; approximately 8 million hectares). In the region of investigation 2,341 sites were placed almost exclusively within the national reserve system (national parks, nature reserves, state conservation areas, community conservation areas, and aboriginal areas) and on privately managed reserves (one Nature Conservation Trust Agreement and two Voluntary Conservation Agreements). Such locations were chosen in order to minimise structural disturbance factors and different management objectives. Seventy-seven private and public conservation areas were surveyed and sites placed randomly within prechosen strata. These strata were generally based on rock type, altitude, aspect, and landform position allowing for replication within each conservation area. No locations were under grazing or any other primary production and the focus of land management was conservation (maintaining or improving current natural condition). Most sample sites were chosen for naturalness. A small number of locations were within previous areas of Cypress Pine (Callitris glaucophylla) logging or thinning programs prior to inclusion within the reserve network. Any locations with extensive overstorey removal were excluded from the primary dataset.

Altitudes ranged from $1,371 \mathrm{~m}$ above sea level at Butterleaf northeast of Glen Innes $\left(29^{\circ} 30^{\prime}, 152^{\circ} 00^{\prime}\right)$ to $122 \mathrm{~m}$ above sea level at Narran Lakes $\left(30^{\circ} 31^{\prime}, 151^{\circ} 30^{\prime}\right)$ in central northwestern New South Wales. The study area is dominated by the Dividing Range which runs southwest along the eastern edge of the region with an associated high altitude tableland area (over $800 \mathrm{~m}$ a.s.l). Altitudes fall to the west levelling to open plains. Some isolated high altitude areas occur in western locations away from the main range (Mt Kaputar $1,300 \mathrm{~m}$; Warrumbungle Range $1,100 \mathrm{~m}$ ). The most northerly sites were within the Yelarbon area $\left(28^{\circ} 42^{\prime}, 140^{\circ} 47^{\prime}\right)$ and the most southerly near Biddon $\left(31^{\circ} 38^{\prime}, 148^{\circ} 48^{\prime}\right)$. Annual mean temperatures range from $11.7^{\circ} \mathrm{C}$ to $20.5^{\circ} \mathrm{C}$ and the annual mean rainfall ranges from $422 \mathrm{~mm}$ to $1,140 \mathrm{~mm}$. Around $60 \%$ of annual rainfall occurs from November to March; thus rainfall is strongly seasonal with a marked summer peak and dry winters. Seasonality increases from south to north. Rainfall is proportionately higher along the far east of the Dividing Range as it receives additional orographic precipitation while the western areas are increasingly within rain shadow. Generally taller forests and closed forests occur along the eastern escarpment with open forests and woodlands dominating in intermediate altitudes and open woodlands and shrublands common within the extreme western and lower altitude locations.

2.2. Site Survey. The method follows that first published by Hunter [27]. A random tree with a minimum diameter at breast height $(130 \mathrm{~cm})(\mathrm{DBH})$ of $10 \mathrm{~cm}$ was chosen as a central tree at each location. From this tree 15 of the closest 


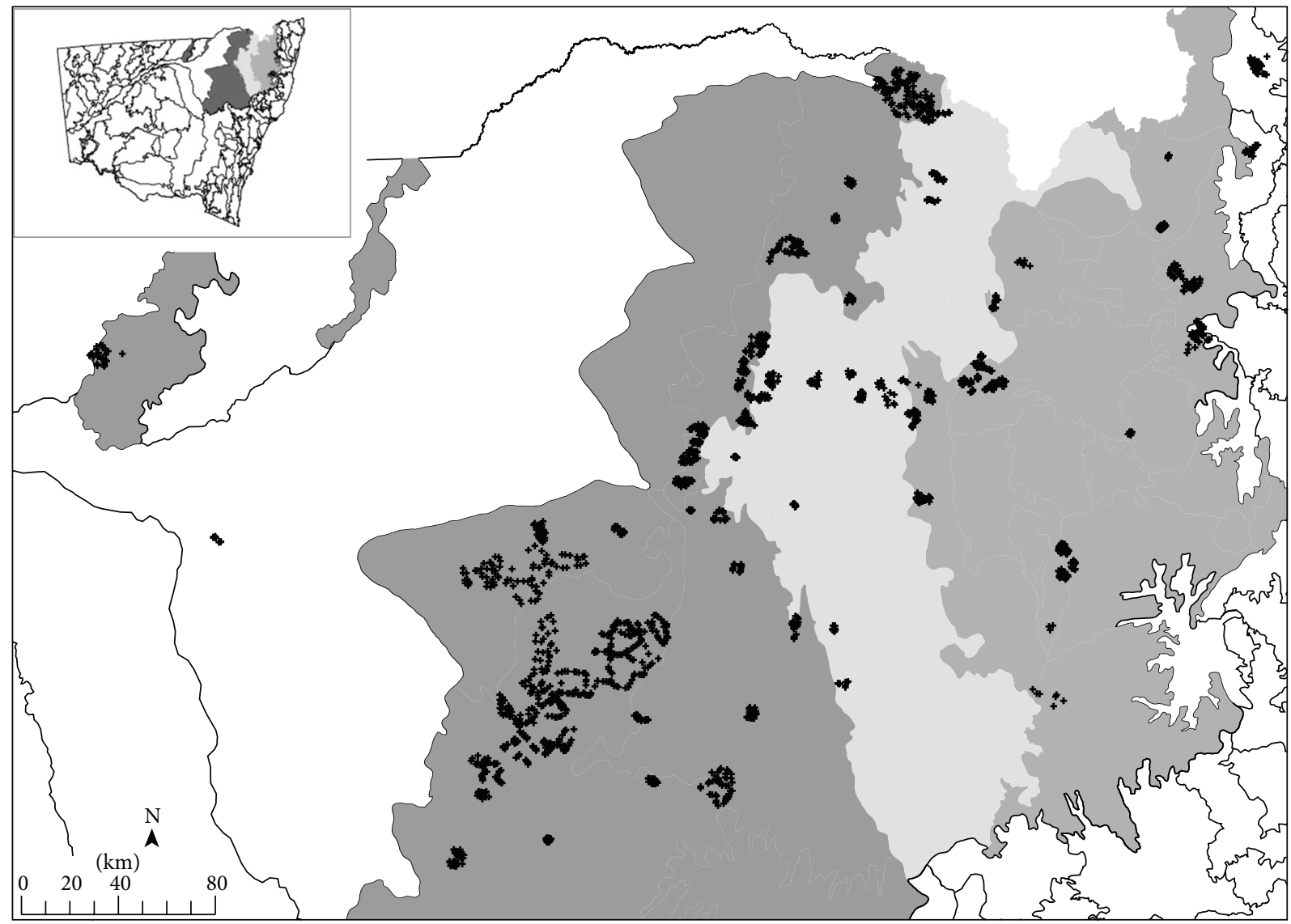

Bioregion
\begin{tabular}{|l}
\hline Nontargeted Bioregions \\
Bioregion name \\
Brigalow Belt South \\
Nandewar \\
New England Tablelands
\end{tabular}

FIGURE 1: Location of 2,341 structural survey sites within northeastern New South Wales.

trees of over $10 \mathrm{~cm} \mathrm{DBH}(130 \mathrm{~cm})$ were recorded $(16$ trees inclusive of the central tree) and the DBH of every stem $>10 \mathrm{~cm} \mathrm{DBH}$ was recorded. The size of these tree sites was unbounded and dependent on the distance to the furthest tree recorded. For each tree the identity of the species and distance to the first tree (meters) were recorded. The size of each site was calculated as the area of the circle whose radius was the distance from the central tree to the furthest tree which enclosed all trees previously recorded. At each location information was gathered on location and altitude with reference to geographical positioning system (GPS; Garman Map 62s; Garmin International, Olathe, KS, USA) along with physiography, soil drainage, and depth. Sites were surveyed over a period of six years (2006 to 2012). The number of hollows (opening diameter $5 \mathrm{~cm}+$ width) visible from ground level (binoculars used where necessary) was recorded for each tree.

2.3. Explanatory Variables. In order to rate how readily some species form hollows, the DBH above which more than $50 \%$ of trees have visible hollows has been calculated as a reference point. Although DBH is commonly used as a surrogate measure for age, this relationship is relative to the ultimate size that is obtainable which varies between species and locations. As different species achieve maturity at different DBH a calibration was attempted whereby the DBH above which more than $50 \%$ of stems have visible hollows was divided by the maximum $\mathrm{DBH}$ measured for that species within the dataset and presented as a percentage. These calculations were made for species with over 200 samples, and for which hollow occurrence was correlated with diameter. A regression analysis for each species with over 200 samples was undertaken to test if there was a significant $(P<0.05 \%)$ relationship between hollow number and $\mathrm{DBH}$.

ANUCLIM 6.1.1 [28] was used to model 35 bioclimatic parameters based on the climate variables maximum temperature, minimum temperature, rainfall, solar radiation, and pan evaporation. Altitude at each site was used to increase the accuracy of the predicted bioclimatic parameters. Geographic positions of latitude and longitude were used as 
variables in analyses along with altitude (elevation above sea level in meters), physiography (crest to open depression, scored 1 to 6 ), soil depth (deep to skeletal, scored 1 to 3 ), drainage (waterlogged to well drained, scored 1 to 4), and plot size, all of which were measured in the field. Thus a total of 41 variables were calculated or scored for each site.

2.4. Statistical Analyses. Species data was presented in the form of two matrices of species by sites. The first matrix was populated by the number of hollows counted for each species at that site. In the second matrix the number of hollows was based on the size of the original plot scaled to one hectare. "Environmental" data was presented as a matrix of factors by sites. The CANOCO5 package [29] was used to test the effects of physical, locational, and climatic variables on the unscaled data hollow number and the dataset scaled to one hectare. This was done in order to test the robustness of results and to quantify the effect of scaling to one hectare. As the response data is compositional and the gradient lengths were 9.4 SD units long, unimodal canonical correspondence analysis (CCA) was considered the most appropriate analysis technique by the advisor module within CANOCO5. Significant environmental variables were chosen by the manual forward selection procedure in CANOCO5, followed by Monte Carlo permutation tests (1000 iterations). Forward selection allows for the removal of collinear/redundant variables from the regression model and subsequent reanalysis of the contribution of the remaining unselected variables as each new variable is added to the model. Holm's correction was used in order to adjust the significance values for potential inflated family-wise Type I errors thus reducing the chances of collinearity and false significance [29]. Only variables which achieved a $P$ value of less than 0.05 after Holm's correction were included within the model.

The effect of significant variables on hollow number was tested using regression modelling. Generalised Additive Modelling (GAM) was used to model the single attribute of hollow number against the constrained ordination space. The fitted GAM is a graphical representation of the relationship between the values of the predictor and its effect on the modelled response variable [30]. Within CANOCO a stepwise model selection occurs, in terms of both predictors used and model complexity. The GAM models of varying complexity are tested within CANOCO and the model with highest parsimony is tested via Akaike information criterion [30].

Though the techniques employed minimise collinearity and redundancy, significant explanatory variables may still contain overlapping marginal and conditional effects on the data [30]. To further attempt to separate the pure effects of the modelled vectors on hollow number, partitioning of variance was conducted between groups of related variables using partial analyses in CCA $[29,31]$. Variation partitioning allows an objective quantification of how the relative influence of variable sets changes over a range of scales [32].

\section{Results}

In total 36,334 individuals were measured from 197 taxa. Of these 79 species and 22,582 individuals were from the genera Angophora, Eucalyptus, or Corymbia. Most of the individuals measured were in the lower size classes with $63.3 \%$ between 10 and $20 \mathrm{~cm} \mathrm{DBH}$ and $25.8 \%$ within the $21-40 \mathrm{~cm} \mathrm{DBH}$ class; thus almost $90 \%$ of individuals had their largest stem below $40 \mathrm{~cm} \mathrm{DBH}$ (Table 1). Only $1.3 \%$ of trees were over $80 \mathrm{~cm}$ $\mathrm{DBH}$ and 460 sites (19.6\%) had trees of this size or larger. $41 \%$ of sites were found to have at least one hollow present. Hollows were found in all size classes though most hollows occurred on individuals with their main stem in the 41$60 \mathrm{~cm}$ size class despite only $58 \%$ of those individuals having hollows. A total of 6,480 visible hollows were recorded. Only $8.1 \%$ of all individuals had recorded visible hollows and the maximum number of hollows recorded on a single individual was 22 . Almost all trees in the $80 \mathrm{~cm}$ and above size class were found with hollows. The maximum number of trees with at least one hollow within a single plot was 10 and the average number was 3 (out of 16).

The DBH above which more than $50 \%$ of individuals have visible hollows has been calculated and calibrated against the largest stem recorded (Table 2). Each species is listed in Table 2 from lowest (top of table) to highest for the calibrated figure. A number of species had very few hollows no matter what size of $\mathrm{DBH}$, or the hollows were dispersed over a range of $\mathrm{DBH}$ sizes, and thus at no point was the $50 \%$ mark obtained. These species represented the majority of nonmyrtaceous taxa (Acacia, Callitris, and Casuarina) but also included a number of Eucalyptus species of various bark types. The species that most readily formed detectable hollows at a younger age cohort included Eucalyptus prava, Eucalyptus camaldulensis, Eucalyptus populnea, and Angophora floribunda. Those species least likely to form detectable hollows included Allocasuarina luehmannii, Eucalyptus sideroxylon, Eucalyptus dealbata, Eucalyptus caliginosa, and Eucalyptus melanophloia.

There was a high degree of congruence between the CCA results for significant variables on hollow numbers from the unscaled hollow dataset (constrained by the distance to the 15th tree) and the dataset scaled to one hectare. Furthermore the plot size was not found to be a significant variable within model. The unscaled dataset explained $14.1 \%$ of the variance in hollow presence and number (28 significant variables) (Table 3). The dataset scaled to one hectare explained $12.6 \%$ (30 significant variables). All the eleven most significant variables from the unscaled data analysis were also of significance in the scaled to one hectare analysis and the top three most significant variables were in the same order of importance. Only five less explanatory significant variables were different in the two analyses. Physiography and drainage were two of the less important variables that did not appear in the scaled one hectare analysis. Due to the high congruence of results, the slightly greater explanatory power with fewer variables and that plot size was not a significant variable; only the raw data results are discussed in detail.

The CCA constrained ordination of unscaled hollow number described $49 \%$ of the total variation with the 
TABLE 1: Distribution of stem sizes and the number of hollows within diameter size classes.

\begin{tabular}{lccc}
\hline Size class & Stems measured & Percent of all hollows & Percent with hollows \\
\hline $10-20 \mathrm{~cm}$ & $63.3 \%$ & 4.7 & 8.6 \\
$21-40 \mathrm{~cm}$ & $25.8 \%$ & 25.1 & 38.1 \\
$41-60 \mathrm{~cm}$ & $7.4 \%$ & 33.7 & 58.0 \\
$61-80 \mathrm{~cm}$ & $2.2 \%$ & 18.9 & 60.7 \\
$80-100 \mathrm{~cm}$ & $0.9 \%$ & 9.4 & 97.0 \\
$100 \mathrm{~cm}$ plus & $0.4 \%$ & 6.6 & 99.0 \\
\hline
\end{tabular}

TABLE 2: Selected features of collected data for species with over 200 samples.

\begin{tabular}{|c|c|c|c|c|c|}
\hline Species & $\mathrm{DBH}(\mathrm{cm})^{*}$ & Sample number & Largest DBH $(\mathrm{cm})$ & Bark type & Age score $^{+}$ \\
\hline Eucalyptus prava & 27 & 430 & 162 & Smooth & 17 \\
\hline Eucalyptus camaldulensis & 35 & 201 & 180 & Smooth & 19 \\
\hline Eucalyptus populnea & 32 & 207 & 120 & Box & 27 \\
\hline Angophora floribunda & 55 & 2056 & 190 & Box & 29 \\
\hline Eucalyptus rossii & 30 & 207 & 100 & Smooth & 30 \\
\hline Eucalyptus albens & 40 & 1450 & 127 & Box & 32 \\
\hline Eucalyptus blakelyi & 57 & 1607 & 180 & Smooth & 32 \\
\hline Eucalyptus bridgesiana & 44 & 248 & 134 & Box & 33 \\
\hline Eucalyptus caleyi & 36 & 267 & 106 & Iron & 34 \\
\hline Eucalyptus pilligaensis & 35 & 481 & 102 & Box & 34 \\
\hline Angophora leiocarpa & 45 & 542 & 120 & Smooth & 38 \\
\hline Eucalyptus conica & 33 & 202 & 86 & Box & 38 \\
\hline Eucalyptus melliodora & 65 & 864 & 170 & Box/smooth & 38 \\
\hline Eucalyptus moluccana & 60 & 427 & 158 & Box & 38 \\
\hline Corymbia trachyphloia & 43 & 1091 & 107 & Tessellated & 40 \\
\hline Eucalyptus caleyi & 44 & 287 & 107 & Iron & 41 \\
\hline Eucalyptus chloroclada & 32 & 390 & 74 & Smooth & 43 \\
\hline Eucalyptus campanulata & 62 & 350 & 138 & Peppermint & 45 \\
\hline Eucalyptus crebra & 54 & 2355 & 120 & Iron & 45 \\
\hline Eucalyptus viminalis & 75 & 198 & 158 & Smooth & 48 \\
\hline Eucalyptus fibrosa & 52 & 1208 & 107 & Iron & 49 \\
\hline Eucalyptus melanophloia & 48 & 923 & 77 & Iron & 62 \\
\hline Eucalyptus caliginosa & 54 & 951 & 123 & Stringy & 68 \\
\hline Eucalyptus dealbata & 56 & 744 & 83 & Smooth & 68 \\
\hline Eucalyptus sideroxylon & 56 & 217 & 85 & Iron & 68 \\
\hline Allocasuarina luehmannii & 59 & 987 & 68 & Fissured & 87 \\
\hline Acacia cheelii & & 248 & 44 & Fissured & NA \\
\hline Acacia harpophylla & & 349 & 83 & Fissured & NA \\
\hline Callitris endlicheri & & 2460 & 74 & Furrowed & NA \\
\hline Callitris glaucophylla & & 5445 & 116 & Furrowed & NA \\
\hline Casuarina cristata & & 387 & 75 & Fissured & NA \\
\hline Casuarina cunninghamiana & & 240 & 131 & Fissured & NA \\
\hline Eucalyptus andrewsii & & 463 & 117 & Peppermint & NA \\
\hline Eucalyptus biturbinata & & 200 & 135 & Smooth & NA \\
\hline Eucalyptus dwyeri & & 258 & 102 & Smooth & NA \\
\hline Eucalyptus macrorhyncha & & 434 & 99 & Stringy & NA \\
\hline Eucalyptus youmanii & & 281 & 110 & Stringy & NA \\
\hline
\end{tabular}

${ }^{*}$ The diameter at which more than $50 \%$ of larger trees contain visible hollows.

${ }^{+}$Age surrogate for point at which hollows become more common as calculated by dividing column one by the largest stem recorded and presenting as a percentage. 
TABLE 3: Codes and descriptions of significant variables $(P \leq 5 \%)$ listed in order of decreasing importance (contribution) from forward selection in plot/hollow biplot analysis.

\begin{tabular}{|c|c|c|c|c|}
\hline Code & Variable explanation & $\begin{array}{c}\text { Percent } \\
\text { contribution }\end{array}$ & $\begin{array}{l}\text { Percent } \\
\text { explained }\end{array}$ & $P$ value (Holm's adj.) \\
\hline MMILQ & Mean moisture index of the lowest quarter & 9.2 & 1.5 & $P<0.05$ \\
\hline RadWaQ & Radiation of the warmest quarter & 6.5 & 1.1 & $P<0.05$ \\
\hline MMIWQ & Mean moisture index of the wettest quarter & 6.2 & 1.0 & $P<0.05$ \\
\hline MTWP & Mean temperature of the wettest period & 5.1 & 0.8 & $P<0.05$ \\
\hline PWP & Precipitation of the wettest period & 5.1 & 0.8 & $P<0.05$ \\
\hline Altitude & Altitude above sea level & 3.8 & 0.6 & $P<0.05$ \\
\hline Longitude & Longitude & 3.7 & 0.6 & $P<0.05$ \\
\hline LPRad & Lowest period of radiation & 3.4 & 0.6 & $P<0.05$ \\
\hline Latitude & Latitude & 2.9 & 0.5 & $P<0.05$ \\
\hline RadWeQ & Radiation of the wettest quarter & 2.8 & 0.5 & $P<0.05$ \\
\hline PWQ & Precipitation of the wettest quarter & 2.8 & 0.5 & $P<0.05$ \\
\hline HPRad & Highest period of radiation & 2.5 & 0.5 & $P<0.05$ \\
\hline PS & Precipitation seasonality & 2.7 & 0.4 & $P<0.05$ \\
\hline MDR & Mean diurnal range & 2.7 & 0.4 & $P<0.05$ \\
\hline Physiography & Position in landscape (crest to open depression) & 2.3 & 0.4 & $P<0.05$ \\
\hline MTWQ & Mean temperature of the wettest quarter & 2.2 & 0.4 & $P<0.05$ \\
\hline AMT & Annual mean temperature & 2.2 & 0.4 & $P<0.05$ \\
\hline PWQ & Precipitation of the wettest quarter & 2.2 & 0.4 & $P<0.05$ \\
\hline PCQ & Precipitation of the coldest quarter & 2.1 & 0.3 & $P<0.05$ \\
\hline MTCQ & Mean temperature of the coldest quarter & 2.0 & 0.4 & $P<0.05$ \\
\hline PDP & Precipitation of the driest period & 2.0 & 0.3 & $P<0.05$ \\
\hline MTCP & Mean temperature of the coldest period & 1.9 & 0.3 & $P<0.05$ \\
\hline MMIHQ & Mean moisture index of the highest quarter & 1.8 & 0.3 & $P<0.05$ \\
\hline RadCQ & Radiation of the coldest quarter & 1.7 & 0.3 & $P<0.05$ \\
\hline LPMI & Lowest period of moisture index & 1.4 & 0.2 & $P<0.05$ \\
\hline Drainage & Drainage (deep to skeletal) & 1.4 & 0.2 & $P<0.05$ \\
\hline MTWQ & Mean temperature of the wettest quarter & 1.4 & 0.2 & $P<0.05$ \\
\hline
\end{tabular}

explanatory variables accounting for $14.1 \%$. The significance of the constrained axes used for the model was individually tested $(P=0.001)$. Of the 28 variables, 12 were considered to be of greater contribution to the model (as each explained a minimum of $0.5 \%$ of variance). Of these, four were associated with moisture (PWP, PDQ, MMILQ, and MMIWQ), three were associated with geographic location (altitude, longitude, and latitude), four were associated with radiation (HPRad, LPRad, RadWeQ, and RadWaQ), and one was associated with temperature (MTWP) (Table 3). The most important variable within the model was MMILQ (Table 3). Only variables that explained at least $0.5 \%$ of variation (11) are presented graphically (Figure 2). The results of GAM indicate a unimodal response of hollow occurrence in respect of the eleven significant variables (Figure 2). This response indicates that there is an initial increase in hollow presence within sites with an increase in MMIWQ, MMILQ, PWQ, altitude, latitude, and LPRad and with a decrease in RadWeQ, RadWaQ, and MTWP. This increase in hollow occurrence then decreases at the more extreme values of these variables. Thus areas corresponding to Nandewar and Brigalow Belt
South Bioregions (Figure 1) are likely to contain the highest number of hollows, locations further to the east and west decreasing in occurrence.

The eleven variables that contributed the most to the CCA model were placed into three groups for variance partitioning analysis to further assess the unique contribution of each type to the overall model. These groups included moisture related variables (PWP, PDQ, MMILQ, and MMIWQ), geographic variables (altitude, latitude, and longitude), and radiation/temperature variables (MTWP, HPRad, LPRad, RadWeQ, and RadWaQ). The partition analysis shows that moisture availability over summer through retention in the soil (moisture index) and by rainfall (precipitation) combined is of greatest predictive power in hollow number within the model (31.1\%) (Figure 3). Variance partitioning scores for the scaled to one hectare dataset and the raw dataset are compared in Figure 2. An increase in the scale (size) of sites increased the importance of moisture related variables $(54.6 \%)$ and decreased the importance of location and radiation/temperature variables in the model. 


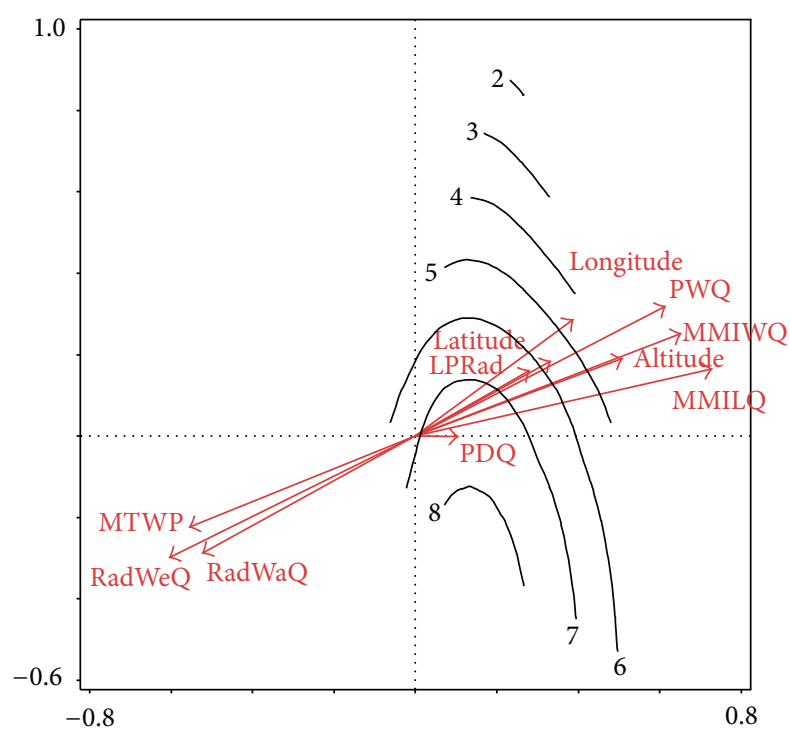

FIgURE 2: Generalised Additive Model based contour plot for tree hollow number per plot against the 11 most significant environmental variables (minimum of $0.5 \%$ contribution) within the CCA model. Codes given in Table 3. Axes represent the first two axes of CCA analysis.

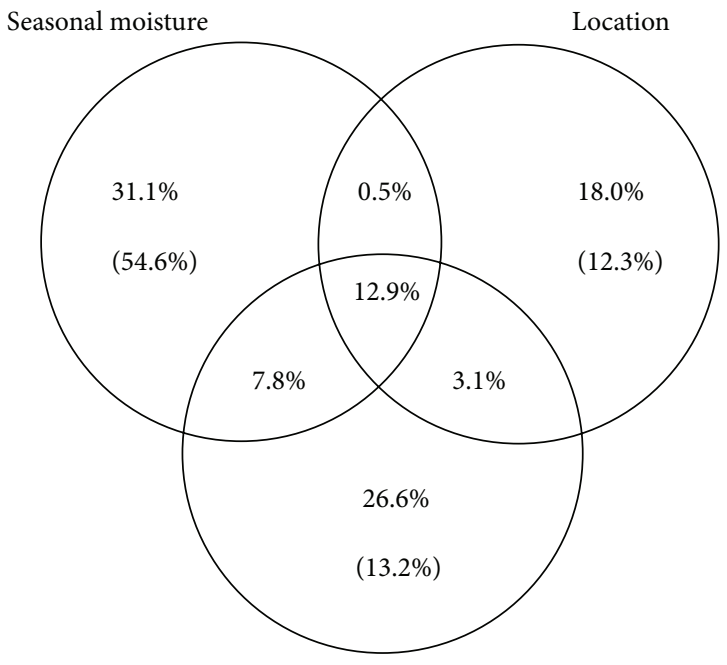

Seasonal radiation/temperature

FIGURE 3: Proportion of explained variation in hollow number within three major groups (values in brackets are those obtained from plot values extrapolated to hectares). Values are percentages of explained variation of the full model (14.1\% inertia).

\section{Discussion}

Vines [17] found that trees with thinner bark (gum and box bark) were more susceptible to fire damage. Brack et al. [18] showed that bark thickness and sapwood cross section were negatively correlated with surrogates for physiological stress. There is some evidence within the dataset to suggest that thinner bark types are more likely to allow hollow formation. Nine out of ten species which ranked within the youngest age classes for hollow formation were smooth or box barked (Table 2). Thus anecdotally increasing thickness of bark may play a role in determining susceptibility of hollow formation and thus number of hollows within the landscape. Species identity was clearly an important component affecting the number of hollows that may be present within a plot.

Spatial variables are more open to interpretation as to the underlying factors that they represent in terms of affecting hollow number and occurrence. In relation to altitude they could include a reduction in photosynthesis due to the decrease in atmospheric pressure [33]. Changes in altitude have also been correlated with differences in soil chemistry and nutrient availability [34]. As the Dividing Range runs southwest the combination of latitude and longitude would be acting along this geographic feature which may include unmeasured physical aspects such as underlying geology and/or floristic and historical evolutionary differences. For instance, longitude is associated with major changes in rock types with primarily alluvial soils to the west and mountains to the east. The far northeast of the study region includes the McPherson-Macleay overlap (border ranges), an area of high endemism, floristic richness, and a meeting point of major biogeographic floristic and faunal elements [35] which dissipates both latitudinally and longitudinally.

The most important variables indicate a seasonality aspect of climate influencing the number of hollows. The study region is mostly covered by a slight summer dominant seasonal climate which increases in intensity to the north. All the climatic variables with the greatest explanatory power in the model (Figure 2) indicate that a seasonality component of climate is of importance. Seasonality of climate, particularly changes in summer, appears to be of significance in hollow distribution with mean moisture index of the lowest quarter (summer), radiation of the warmest quarter (summer), mean moisture index of the wettest quarter (summer), mean temperature of the wettest period (summer), precipitation of the wettest period (summer), lowest period of radiation (summer), and radiation of the wettest quarter (summer) all being summer related variables. Variance partitioning clearly indicated that significant seasonal moisture variables accounted for highest percentage of unique variance in hollow numbers (Figure 3).

The results obtained here partially agree with the results of Lindenmayer et al. [8] and Bennett et al. [14] who showed that higher rainfall areas with low temperatures have less hollows per site; however in this dataset the more extreme locations of low rainfall and higher temperatures also had a decrease in hollow number. Furthermore these previous studies did not test aspects of seasonality. The investigation of Lindenmayer et al. [8] was conducted within the central highlands of Victoria which lies in the aseasonal rainfall zone. Bennett et al. [14] carried out their investigation across a rainfall gradient of $370-400 \mathrm{~mm}$, with only 13 species within a winter maximum rainfall zone. Thus differences in scale and rainfall seasonality could in part explain the more complex results found here.

The CCA model suggests that summer rainfall, rather than annual rainfall, and summer retention of moisture were of most importance in predicting hollow number at this 
landscape scale of investigation (Figures 2 and 3) within the summer seasonal climate zone. The results are however unimodal. There was a negative correlation with drainage and physiography indicating an increase in lower topographic positions towards valley floors, open depressions, and locations that are waterlogged having a reduced number of hollows (Table 3). Like the landscape level results, local situations with an increase in moisture retention had lower number of hollows. This may be because locations of higher site productivity may contain species with higher growth rates which may not form hollows as readily $[12,14,15]$. This is in contrast to Lindenmayer et al. [8] and Soderquist and Mac Nally [19] who found an increase in trees with hollows in gullies compared to ridge tops and crests. The results herein support those of Eyre [15] who found less hollows in gullies. While Lindenmayer et al. [12] suggested that steeper slopes may have greater number of hollows, slope was not found to be a significant variable in hollow number. The insignificance of slope within the CCA model may be due to the large scale of this investigation masking localised site factors which is typical of large scale analyses [24]. Comparison with the dataset scaled to one hectare provides evidence for this as the higher scale investigation reduced the importance of local factors such as physiographic position and drainage and increased the importance of the major climatic variables (Figure 2).

It is predicted that annual rainfall may not change appreciably in the near future within northeastern NSW [36, 37]. It is likely that temperatures will rise, affecting the ability of the landscape to retain moisture (decreasing moisture index values) and showing an increase in precipitation seasonality. Changes in summer moisture retention and rainfall were the most significant factors in the model for hollow number along with changes in summer temperature and radiation. It is thus likely that the region of highest number of hollows will move easterly and up in altitude if taxonomic replacement can occur. This process is likely to be slow and would also require species to reach a level of maturity where hollows become more common. Such changes are likely to require many hundreds of years $[4,5,7]$. Extreme events such as greater severity of droughts and fires may also be more prevalent and intense. Such events may cause an increase in damage to stems and death of individuals causing an initial increase in hollow number. However, the synergistic increase in the severity of droughts and fires are likely to reduce the number of older stems within stands through death and collapse [24, $38-40]$. Climate change is likely to cause a geographic shift in the optimum zone for hollow resources within northeast and western NSW but only if species replacement through dispersion and colonisation is allowed to occur. Under this scenario a rapid change in climate seasonality over several decades may cause a significant redistribution of a vital attribute such as hollows that may require many hundreds of years before significant numbers can be reestablished. Much research has been conducted showing significant declines in the tree hollow resource due to clearing of vegetation for agriculture and other purposes. The results presented here indicated for the first time that even if all clearing of the tree hollow were to cease a continued decline is likely to occur due to shifts in moisture balance to climate change within eastern Australia.

Estimates suggest that globally 500 species of bats and 260 bird species rely on tree hollows at some point in their life cycle [3]. Within Australia 26 species of hollow reliant birds and mammals are listed as threatened by federal and state legislation [3]. Isaac et al. [7] suggest that Australian faunal assemblages are more dependent on hollows than those of other continents. Obligate hollow users occur across all tropic levels and can include a predator and the majority of its prey [7]. Many insects are kept in control by hollow dependent fauna such as bats [3]. In areas with reduced hollow numbers fauna using such a resource must compete for the increasingly restricted resource. Such competition is both inter- and intraspecific in origin. Introduced species are often in competition for the remaining hollows such as introduced species, for example, the honeybee (Apis mellifera), the common myna (Acridotheres tristis), and the starling (Sturnus vulgaris) [3]. Common native species may also outcompete rarer species for the dwindling hollow resource [3, 41]. Reduction in hollows will significantly decrease the ability of the landscape to support resilient marsupial assemblages which will have flow on effects across the functioning of whole ecosystems within eastern Australia [7].

If we do not thoroughly consider all long term lag effects and risks to important functional resources such as tree hollows we are at a disadvantage in our formulation of threat assessments [5]. In order to secure populations of hollow dependent fauna stopping all clearing will not halt a decline in this vital resource in eastern Australia and thus other measures may need to be considered that encourage and increase replacement within the landscape. Not proceeding immediately with such actions will greatly increase the long term risk of extinction of hollow dependent species.

\section{Conclusion}

The number of hollows is correlated primarily with moisture retention and rainfall during summer within the summer dominant seasonal climate of northeastern New South Wales in eastern Australia. Anthropogenic climate change through increasing temperatures, precipitation seasonality, and reduction in moisture retention along with increasing severity and frequency of fire and drought will likely cause a shift in the optimal location for hollow formation and retention to higher altitudes towards the southeast of the study region. This change can only occur if there is a replacement in species identity along this gradient. As hollows take over 100 years to form there is likely to be an extensive lag time between the pressure caused by a changing climate and the ability of communities to move across an anthropogenically fragmented landscape. Thus in the near future there may be an overall reduction in the number of hollows within this study region until a new equilibrium is reached. The results verify the need to consider the seasonality aspects of climate within analyses of important functional traits of ecosystems. This research shows the importance of considering how vital functional attributes within a landscape are likely to change in concert with changing composition driven by altered climate 
and how this may have significant implications for associated species dependent on such a resource.

\section{Conflict of Interests}

The author declares that there is no conflict of interests regarding the publication of this paper.

\section{Acknowledgments}

Though the inventory was collected by the author he wishes to thank the following who helped with measurements at various times over the six years: Daniel Bailey, Dorothy Bell, Gary Chorley, Peter Croft, Sean Forde, Rachael Gleeson, Zak Growns, Darren Hall, Stephen Hammond, Wendy Hawes, Alan Hill, Briannon Hunter, Calliden Hunter, Vanessa Hunter, Peter Jobson, Jason Kreis, Michael Leiberman, Alex Pawlow, Kate Smillie, Jessica Stokes, and Duncan Vennell.

\section{References}

[1] G. Moreau, D. Fortin, S. Couturier, and T. Duchesne, "Multilevel functional responses for wildlife conservation: the case of threatened caribou in managed boreal forests," Journal of Applied Ecology, vol. 49, no. 3, pp. 611-620, 2012.

[2] D. Vickers, J. T. Hunter, and W. Hawes, "Multiple species use of a water-filled tree hollow by vertebrates in dry woodland habitat of northern New South Wales," Australian Zoologist, vol. 37, no. 2, pp. 134-138, 2014.

[3] R. L. Goldingay, "Characteristics of tree hollows used by Australian birds and bats," Wildlife Research, vol. 36, no. 5, pp. 394409, 2009.

[4] T. Ranius, M. Niklasson, and N. Berg, "Development of tree hollows in pedunculate oak (Quercus robur)," Forest Ecology and Management, vol. 257, no. 1, pp. 303-310, 2009.

[5] A. D. Manning, P. Gibbons, J. Fischer, D. L. Oliver, and D. B. Lindenmayer, "Hollow futures? Tree decline, lag effects and hollow-dependent species," Animal Conservation, vol. 16, no. 4, pp. 395-403, 2013.

[6] F. Carvalho, R. Carvalho, A. Mira, and P. Beja, "Use of tree hollows by a Mediterranean forest carnivore," Forest Ecology and Management, vol. 315, pp. 54-62, 2014.

[7] B. Isaac, J. White, D. Ierodiaconou, and R. Cooke, "Urban to forest gradients: suitability for hollow bearing trees and implications for obligate hollow nesters," Austral Ecology, vol. 39, no. 8, pp. 963-972, 2014.

[8] D. B. Lindenmayer, R. B. Cunningham, H. A. Nix, M. T. Tanton, and A. P. Smith, "Predicting the abundance of hollow-bearing trees in montane forests of southeastern Australia," Australian Journal of Ecology, vol. 16, no. 1, pp. 91-98, 1991.

[9] P. Gibbons, D. B. Lindenmayer, S. C. Barry, and M. T. Tanton, "Hollow formation in eucalypts from temperate forests in Southeastern Australia," Pacific Conservation Biology, vol. 6, no. 3, pp. 218-228, 2000.

[10] J. A. Seddon, S. V. Briggs, and S. J. Doyle, "Relationships between bird species and characteristics of woodland remnants in central New South Wales," Pacific Conservation Biology, vol. 9, no. 2, pp. 95-119, 2003.

[11] T. Greaves and R. G. Florence, "Incidence of termites in Blackbutt regrowth," Australian Forestry, vol. 30, no. 2, pp. 153161, 1966.
[12] D. B. Lindenmayer, R. B. Cunningham, C. F. Donnelly, M. T. Tanton, and H. A. Nix, "The abundance and development of cavities in Eucalyptus trees: a case study in the montane forests of Victoria, southeastern Australia," Forest Ecology and Management, vol. 60, no. 1-2, pp. 77-104, 1993.

[13] L. Rayner, M. Ellis, and J. E. Taylor, "Hollow occurrence and abundance varies with tree characteristics and among species in temperate woodland Eucalyptus," Austral Ecology, vol. 39, no. 2, pp. 145-157, 2014.

[14] A. F. Bennett, L. F. Lumsden, and A. O. Nicholls, "Tree hollows as a resource for wildlife in remnant woodlands: spatial and temporal patterns across the northern plains of Victoria, Australia," Pacific Conservation Biology, vol. 1, pp. 222-235, 1994.

[15] T. J. Eyre, "Hollow-bearing trees in large glider habitat in southeast Queensland, Australia: abundance, spatial distribution and management," Pacific Conservation Biology, vol. 11, no. 1, pp. 2337, 2005.

[16] S. Munks, M. Wapstra, S. R. Corkrey, H. Otley, G. Miller, and B. Walker, "The occurence of potential tree hollows in the dry Eucalypt forests of south-eastern Tasmania, Australia," Australian Zoologist, vol. 34, no. 1, pp. 22-36, 2007.

[17] R. G. Vines, "Heat transfer through bark, and the resistance of trees to fire," Australian Journal of Botany, vol. 16, no. 3, pp. 499$514,1968$.

[18] C. L. Brack, M. P. Dawson, and A. M. Gill, "Bark, leaf and sapwood dimensions in Eucalyptus," Australian Forestry, vol. 15, pp. 1-7, 1985.

[19] T. R. Soderquist and R. Mac Nally, “The conservation value of mesic gullies in dry forest landscapes: mammal populations in the box-ironbark ecosystem of southern Australia," Biological Conservation, vol. 93, no. 3, pp. 281-291, 2000.

[20] P. Whetton, "Future Australian climate scenarios," in Climate Change: Science and Solutions for Australia, H. Cleugh, S. Smith, M. Battaglia, and P. Graham, Eds., CSIRO, Canberra, Australia, 2011.

[21] B. B. Lamont and A. Markey, "Biogeography of fire-killed and resprouting Banksia species in south-western Australia," Australian Journal of Botany, vol. 43, no. 3, pp. 283-303, 1995.

[22] R. M. Cowling and A. T. Lombard, "Heterogeneity, speciation/extinction history and climate: explaining regional plant diversity patterns in the Cape Floristic Region," Diversity and Distributions, vol. 8, no. 3, pp. 163-179, 2002.

[23] J. T. Hunter, "Geographic variation in plant species richness patterns within temperate eucalypt woodlands of eastern Australia," Ecography, vol. 28, no. 4, pp. 505-514, 2005.

[24] J. T. Hunter and D. M. Bell, "Season and timing of moisture availability predict composition of montane shrub-dominated wetlands at distributional limits in eastern Australia," Australian Journal of Botany, vol. 61, no. 4, pp. 243-253, 2013.

[25] P. Gibbons and D. B. Lindenmayer, "The hollow using fauna of Australia," in Tree Hollows and Wildlife Conservation in Australia, pp. 4-19, CSIRO Publishing, Collingwood, Australia, 2002, http://www.publish.csiro.au/pid/3010.htm.

[26] R. Thackway and I. D. Cresswell, An Interim Biogeographic Regionalisation for Australia: A Framework for Setting Priorities in the National Reserves System Cooperative Program, Version 4.0, Australian Nature Conservation Agency, Canberra, Australia, 1995.

[27] J. T. Hunter, "Interactions between Callitris above-ground biomass, species density and plant form in north-eastern New South Wales," Australian Journal of Botany, vol. 61, no. 1, pp. 7379, 2013. 
[28] T. Xu and M. Hutchinson, ANUCLIM 6.1., Australian National University, Canberra, Australia, 2011.

[29] C. J. F. ter Braak and P. Šmilauer, CANOCO Reference Manual and Users Guide Software for Ordination, Version 5.0, Microcomputer Power, Ithaca, NY, USA, 2012.

[30] P. Šmilauer and J. Lepš, Multivariate Analysis of Ecological Data using Canoco 5, Cambridge University Press, Cambridge, UK, 2014.

[31] D. Borcard, P. Legendre, and P. Drapeau, "Partialling out the spatial component of ecological variation," Ecology, vol. 73, no. 3, pp. 1045-1055, 1992.

[32] L. Reino, P. Beja, and A. C. Heitor, "Modelling spatial and environmental effects at the edge of the distribution: the redbacked shrike Lanius collurio in Northern Portugal," Journal of Biogeography, vol. 12, pp. 379-387, 2006.

[33] J. Gale, "Availability of carbon-dioxide for photosynthesis at high-altitudes: theoretical considerations," Ecology, vol. 53, no. 3, pp. 494-497, 1972.

[34] H. Culmsee, C. Leuschner, G. Moser, and R. Pitopang, "Forest aboveground biomass along an elevational transect in Sulawesi, Indonesia, and the role of Fagaceae in tropical montane rain forests," Journal of Biogeography, vol. 37, no. 5, pp. 960-974, 2010.

[35] M. D. Crisp, S. Laffan, H. P. Linder, and A. Munro, "Endemism in the Australian flora," Journal of Biogeography, vol. 28, no. 2, pp. 183-198, 2001.

[36] K. Hennessy, C. Page, K. McInnes, R. Jones, and A. Bathols, Climate Change in New South Wales. Part 1: Past Climate Variability and Projected Changes in Average Climate, CSIRO, Australian Government Bureau of Meteorology, Canberra, Australia, 2004.

[37] PMSEIC Independent Working Group, "Climate change in Australia: regional impacts and adaptation-managing risk for Australia," Report Prepared for the Prime Minister's Science, Engineering and Innovation Council (PMSEIC), PMSEIC, Canberra, Australia, 2007.

[38] P. Croft, J. T. Hunter, and N. Reid, "Depletion of regenerative bud resources during cyclic drought: what are the implications for fire management?" Ecological Management and Restoration, vol. 8, no. 3, pp. 187-192, 2007.

[39] P. Croft, J. T. Hunter, and N. Reid, "Threat of frequent fire and drought for the rare wattle Acacia williamsiana J. T. Hunter: an experimental burn highlights implications for fire management," Ecological Management and Restoration, vol. 11, no. 3, pp. 217-220, 2010.

[40] C. M. McLean, R. Bradstock, O. Price, and R. P. Kavanagh, "Tree hollows and forest stand structure in Australian warm temperate Eucalyptus forests are adversely affected by logging more than wildfire," Forest Ecology and Management, vol. 341, pp. 37-44, 2015.

[41] A. Davis, R. E. Major, and C. E. Taylor, "Housing shortages in urban regions: aggressive interactions at tree hollows in forests remnants," PLoS ONE, vol. 8, Article ID e59332, 2013. 

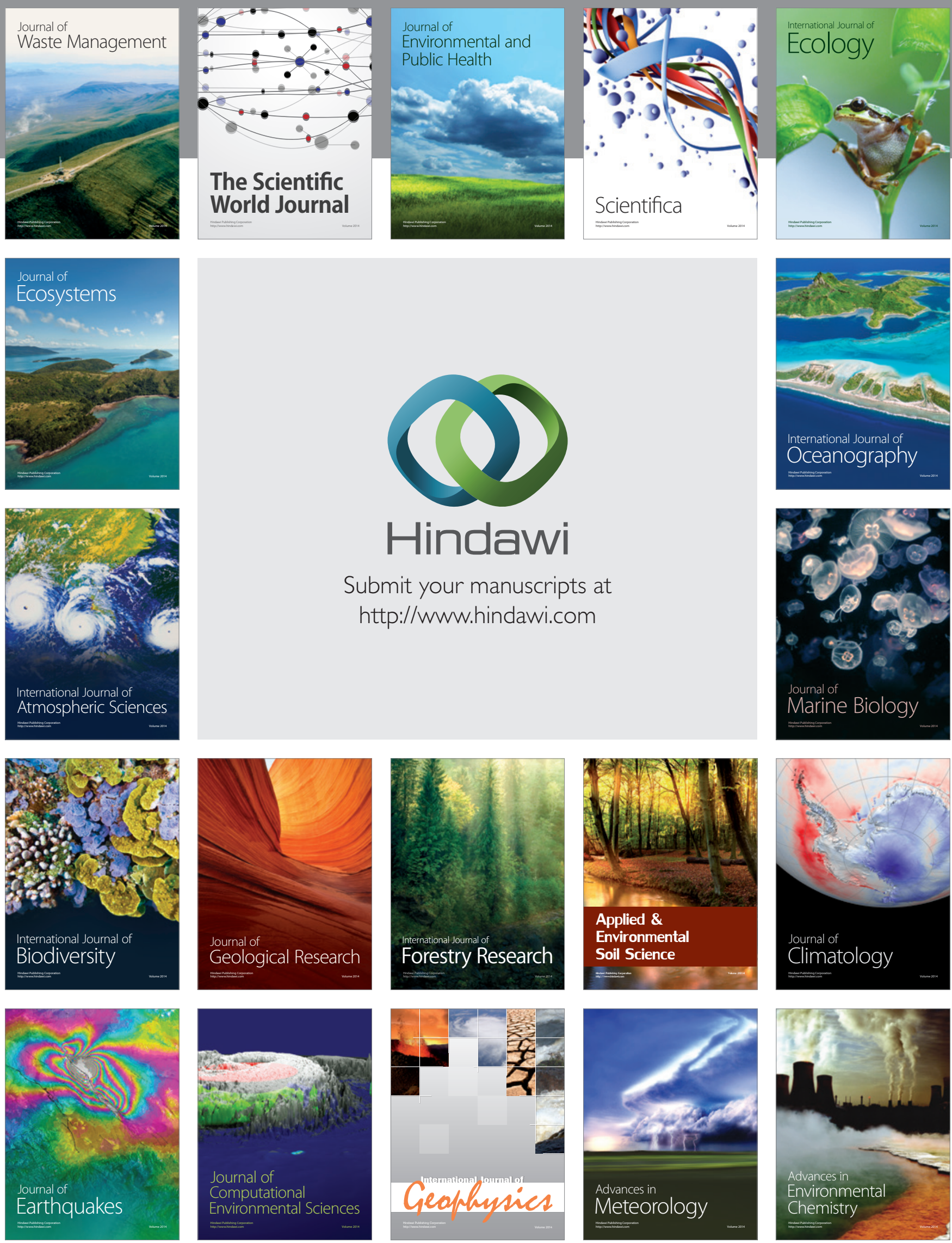